\title{
Investigation report on the demand for skilled talents of fishery enterprises in east China
}

\author{
Xiaojiang Chen", Wei Li $^{2}$, Quan Wang ${ }^{3, *}$ \\ 1, 2,3 Jiangsu Agri-animal Husbandry Vocational College, Taizhou City, Jiangsu Province, China \\ *Corresponding author’email: cq_cxj@126.com
}

Keywords: Fishery enterprises; Skilled talents; Fishery talents

\begin{abstract}
In order to find out the demand for talents in fishery industry in east China and the requirements of fishery talents demand type, level, structure, quantity, quality and other aspects, scientifically analyze and predict the future demand for talents, the author conducts research through online questionnaires and direct interviews. The results show that the most important problem faced by fishery-related enterprises at present is that the number of talents training cannot keep up with the needs of enterprises. the government, colleges and universities, and society should work together to solve the problem of difficult professional enrollment and cultivate professional talents who can endure hardship, love jobs, work hard and have strong skills.
\end{abstract}

\section{Background of investigation}

The three documents of the CPC central Committee and the state Council on the implementation of the rural revitalization strategy [1], the construction plan for the modern vocational education system (2014 - 2020) [2] and the 13th five-year plan for the development of the national fisheries industry [3] have pointed out the direction, objectives and ways for the development of agricultural vocational education. With the deepening of the transformation of the fishery industry to the provincial level, new and higher requirements have been put forward for the talents supporting the development of the fishery industry. there is an urgent need for structural changes in the types, quantity and quality of fishery practitioners. Previous studies have also been done [4,5]. The investigation report is helpful to find out the demand for talents in the fishery industry in east China. Find out the requirements on the type, level, structure, quantity, quality and other aspects of the demand for fishery talents, and scientifically analyze and predict the demand for talents in the future.

\section{Investigation methods}

This survey adopts the method of combining online survey, offline survey and analysis. from May 1, 2018 to July 1, 2018, the survey team conducted this survey activity by visiting well-known enterprises, major talent markets and online questionnaires. a total of 125 questionnaires were distributed and 120 valid questionnaires were retrieved.

\section{Analysis of investigation results}

\subsection{The enterprise situation}

\subsubsection{Nature of the enterprise}

Among the Fishery enterprises involved in this survey, $85.71 \%$ were private enterprises, $3.57 \%$ were state-owned enterprises and $3.57 \%$ were joint ventures, and $7.14 \%$ were others. $32.14 \%$ of the surveyed enterprises are not leading enterprises, and $32.14 \%, 17.86 \%, 14.29 \%$ and $3.57 \%$ of them are national, provincial, municipal and county leading enterprises respectively.

\subsubsection{Main areas of the enterprise}


Among the Fishery enterprises surveyed, the main sectors covered mainly fish medicine production and management, feed production and management, aquaculture and others, accounting for $42.86 \%, 39.29 \%, 14.29 \%$ and $3.57 \%$ respectively. The production and management of fish medicine and feed are the main fields of Fishery enterprises.

\subsubsection{Enterprise personnel structure}

101 - 200 people-sized enterprises accounted for $42.86 \%$, followed by $35.71 \%$ of enterprises with less than 100 people, followed by $14.29 \%$ of enterprises with 501 - 1000 people and $7.14 \%$ of enterprises with 201 - 500 people.

As can be seen from figure 5 - figure 8, the structure of enterprise academic qualifications shows that $78.57 \%$ of enterprises have 1 - 10 employees with postgraduate educational qualifications, $17.86 \%$ have 11 - 15 employees with postgraduate educational qualifications, and only $3.57 \%$ have more than 20 employees with postgraduate educational qualifications. The number of employees with bachelor degree is $32.14 \%, 21$ - 30 employees with bachelor degree is higher, $28.57 \%$, more than 31 employees with bachelor degree, $21.43 \%, 1$ - 10 employees with bachelor degree, and 17.86 \%, 11 - 20 employees with bachelor degree. Professional education: 42.86 \% of employees with professional education in enterprises are above $31,25 \%$ of employees with professional education in enterprises are between 11 and 20, $17.68 \%$ of employees with professional education in enterprises are between 1 and 10 , and $14.29 \%$ of employees with professional education in enterprises are between 21 and 30. 32.14 \% of enterprise high schools and below have more than 50 employees with academic qualifications, $35.71 \%$ of enterprise high schools and below have 1 - 15 employees with academic qualifications, $25 \%$ of enterprise high schools and below have 16 - 30 employees with academic qualifications, and $7.14 \%$ of enterprise high schools and below have 31 - 50 employees with academic qualifications. SPSS software was used to analyze the reliability of the data. the reliability coefficient value was 0.854 , which was greater than 0.8 , thus indicating that the reliability of the research data was of high quality.

\subsection{The demand of enterprises for talents}

The main research enterprises require talents with academic qualifications, higher vocational graduates' positions, the number of recruits to meet the situation, the number of demand in the next 3 to 5 years.

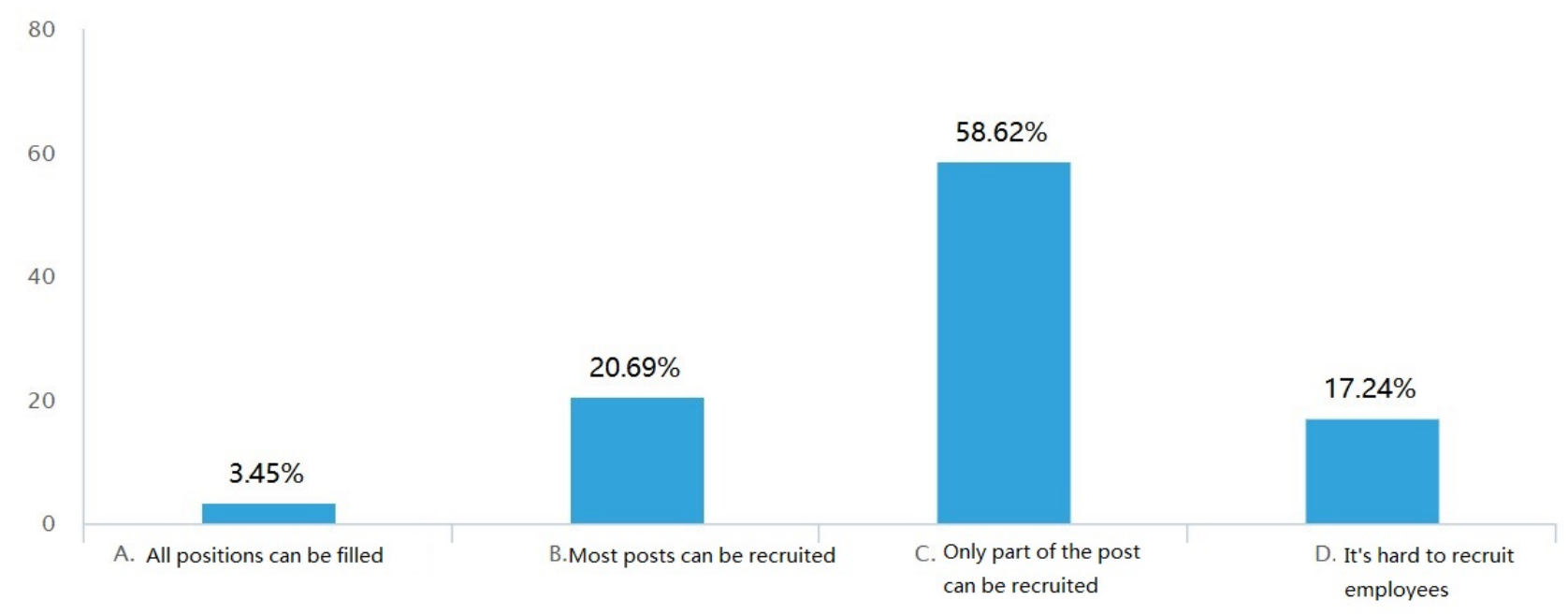

Figure 1 difficulties in recruiting fishery professionals required in previous years 


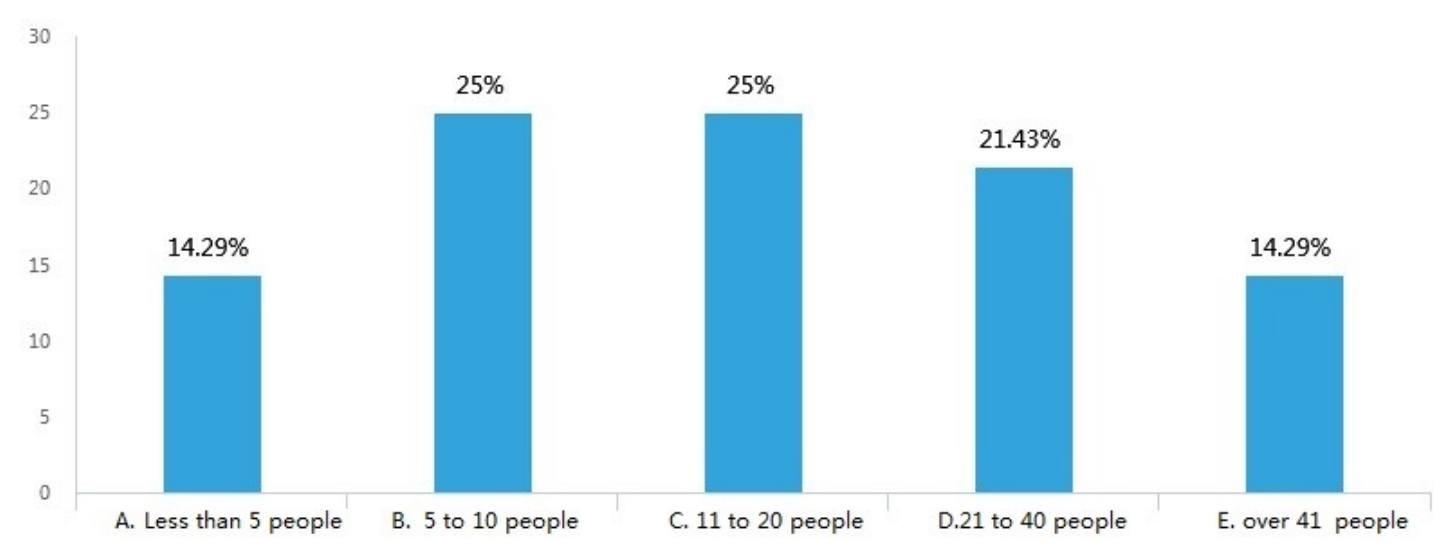

Figure 2 number of fishery graduates required in the next 3 - 5 years

Survey data on the requirements of research enterprises for talents' academic qualifications show that $96.43 \%$ of enterprises have an educational background of at least junior college or above for fishery professionals, while the minimum educational background is only $3.57 \%$ of those with bachelor's degree or above. this reflects from the side that students with bachelor's degree or above are unwilling to enter the frontline jobs of enterprises to engage in the most needed sales or technical service positions, and enterprises have reduced the educational background requirements because they cannot recruit people. from another perspective, students with junior college degree are more practical and popular with enterprises.

The recruitment positions were mainly for marketing personnel and technical personnel, accounting for $50 \%$ and $46.43 \%$ respectively, while other production personnel accounted for only $3.57 \%$. Figure 1 shows that only $58.62 \%$ of the enterprises in the past years have recruited some talents, accounting for $20.69 \%$ of them, $17.24 \%$ of them are hard to recruit, and only $3.45 \%$ of them are satisfied. Figure 2 shows that in the next 3 - 5 years, $25 \%$ of the people need 5 - 10 people and 11 - 20 people each, $21.43 \%$ of the people need 21 - 40 people, and $14.29 \%$ of the people need less than 5 people and more than 40 people each.

Through the correlation analysis of the data of each group by SPSS software, it was found that the enterprise's academic qualifications for fishery professionals had a significant negative correlation with the number of employees $(\mathrm{p}<0.05)$, while the number of employees had a significant positive correlation with the number of employees with different levels of academic qualifications $(\mathrm{p}<0.01)$.

\subsection{Requirements of enterprises on the quality of fishery professionals}

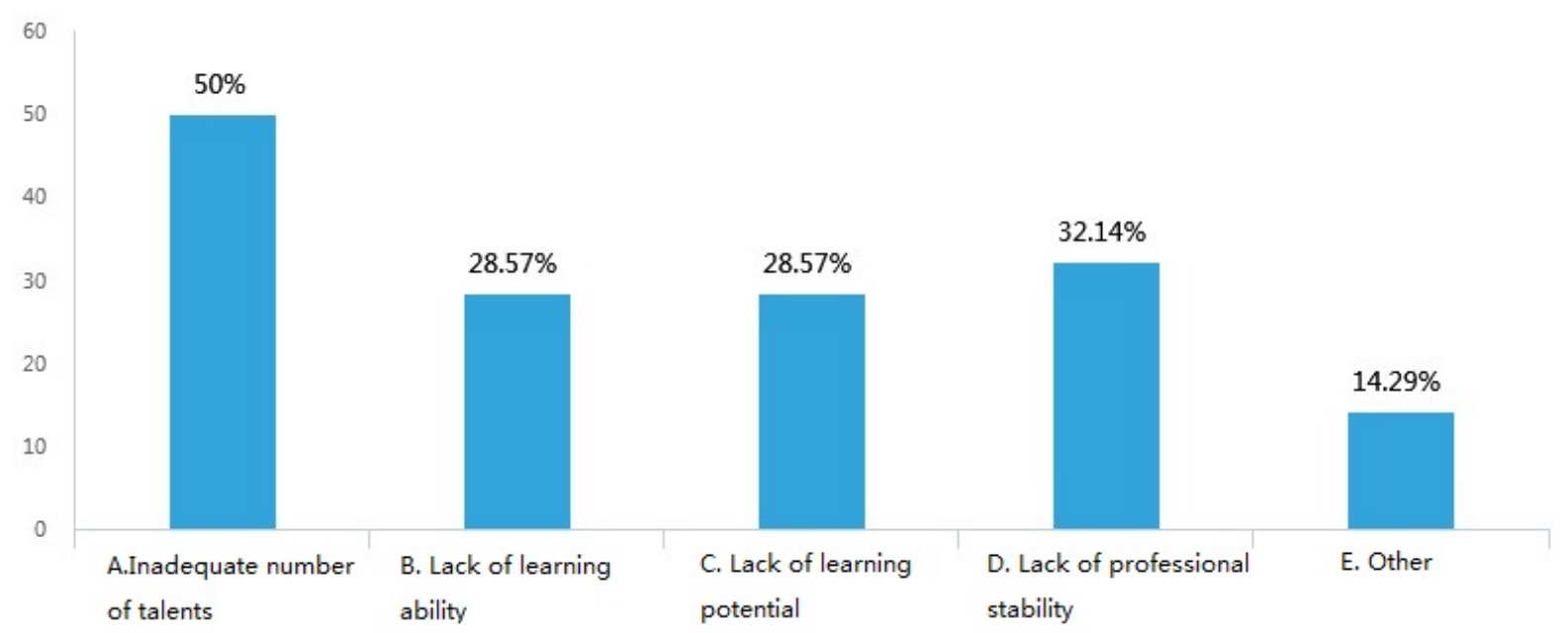

Figure 3 is the least satisfied with the current fishery professionals in higher vocational colleges 


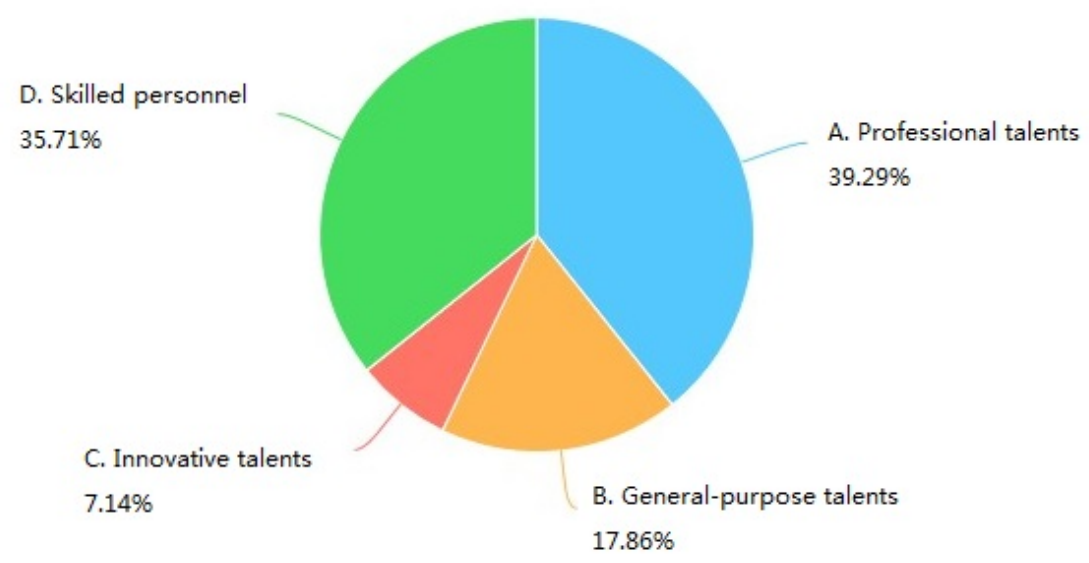

Figure 4 Types of fishery professionals in higher vocational colleges

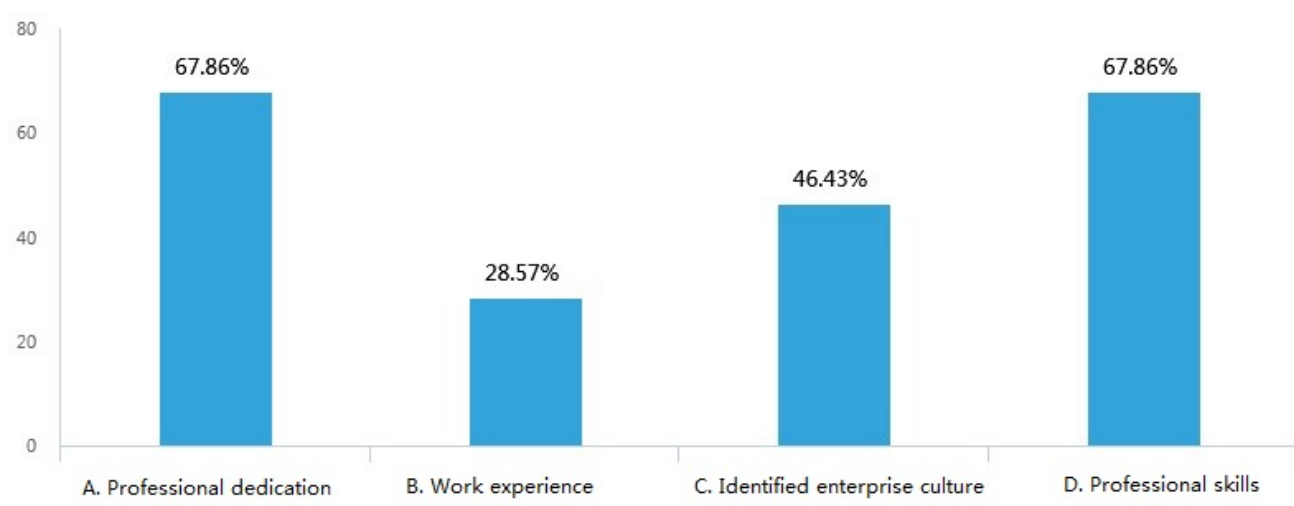

Figure 5 Hopes that fishery professionals in higher vocational colleges should be strengthened (multiple choices)

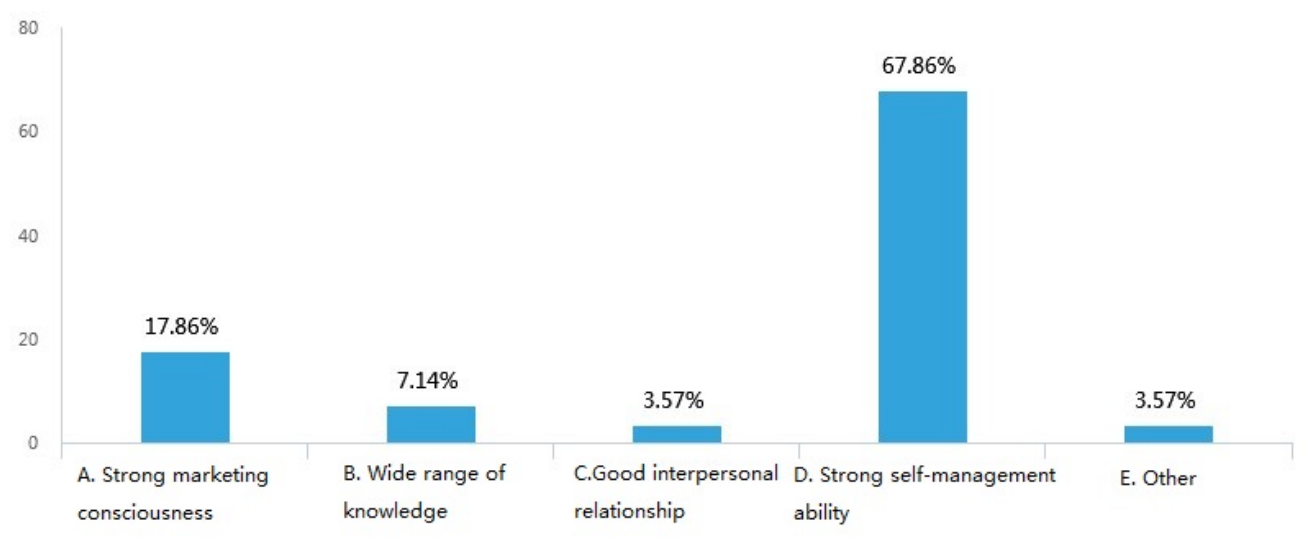

Figure 6 Ability requirements of enterprises for fishery professionals in higher vocational colleges

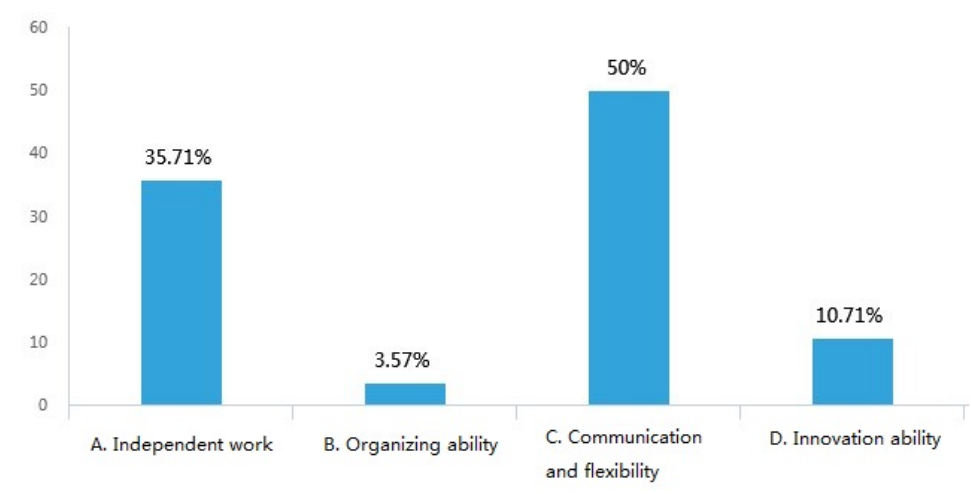

Figure 7 enterprise's competence to fishery professionals in higher vocational colleges 
The fishery industry is much laborious. $53.57 \%$ of enterprises are most looking forward to cultivating talents of fishery specialty in higher vocational colleges to bear hardships, $25 \%$ of enterprises are most looking forward to cultivating talents of fishery specialty in higher vocational colleges to love learning, and $17.86 \%$ of enterprises are most looking forward to cultivating talents of fishery specialty in higher vocational colleges to be loyal to enterprises. Most dissatisfied with the current fishery professionals in higher vocational colleges (figure 3 shows multiple choices), $50 \%$ of the enterprises chose a lack of quantity, $32.14 \%$ chose a lack of professional stability, easy to change jobs or jobs, $28.57 \%$ chose a lack of learning ability, and $28.57 \%$ chose a lack of stamina. Figure 4 shows that enterprises expect to cultivate professional and skilled talents of fishery specialty in higher vocational colleges, accounting for $39.29 \%$ and $35.71 \%$ respectively, general-purpose talents accounting for $17.86 \%$ and innovative talents accounting for $7.14 \%$. Which options are expected to be strengthened in the cultivation of fishery talents in higher vocational colleges (figure 5, multiple choices), $67.86 \%$ of enterprises choose to strengthen their professionalism and professional skills respectively, $46.43 \%$ choose to strengthen their cultural identity, and $28.57 \%$ choose to strengthen their accumulated working experience. Figure 6 shows that $67.86 \%$ of enterprises require talents with strong self-management ability, while $17.86 \%$ of enterprises require talents with marketing awareness. Figure 7 shows that $50 \%$ of enterprises require talents to communicate with each other and $35.71 \%$ require talents to have the ability to work independently. The survey also showed that $50 \%$ of enterprises believed that the teaching reform of fishery specialty should pay attention to the teaching methods, $35.71 \%$ should pay attention to the latest technology, and $14.29 \%$ should pay attention to the latest model.

\section{Summary and suggestions}

The employment channels for fishery talents are mainly $82.15 \%$ in fish medicine production and management, $82.15 \%$ in feed production and management, and about $14.29 \%$ in aquaculture enterprises, while the positions are mainly marketing personnel and technical personnel, accounting for $50 \%$ and $46.43 \%$ respectively and $96.43 \%$ in total. therefore, the current demand for fishery talents in the industry is mainly in the field of technical services. Most of the employment of fishery talents is concentrated in enterprises with 101 - 200 employees and enterprises with less than 100 employees, accounting for $42.86 \%$ and $35.71 \%$ respectively, $14.29 \%$ of enterprises with more than 500 employees and $7.14 \%$ of enterprises with 201 - 500 employees.

Through investigation, it was found that $78.57 \%$ of the enterprises involved in Fishery enterprises had a graduate degree of 1 to 10 employees, while the proportion of 21 to 30 employees with a bachelor's degree or above was $32.14 \%$ and $28.57 \%$ of the employees with a bachelor's degree or above. The number of employees with specialized educational background is $42.86 \%$ at most, followed by 11 to 20, accounting for $25 \%$. $32.14 \%$ of enterprises with more than 50 employees and $35.71 \%$ of enterprises with 1 - 15 employees have technical secondary school - high school education or below. Workers with secondary and lower secondary school qualifications are mainly in the production department. $96.43 \%$ of enterprises require minimum tertiary education for fishery professionals. the demand for technical and marketing departments is strong. over the years, recruitment positions are mainly concentrated in marketing personnel and technical personnel, accounting for $50 \%$ and $46.43 \%$ respectively. The data also shows that there is a serious shortage of talent recruitment in enterprises. only $58.62 \%$ of enterprises have recruited some talents, accounting for $20.69 \%$ of the total, $17.24 \%$ of which are hard to recruit, and only $3.45 \%$ of which are satisfied. In the next 3 - 5 years, there is still a big gap in demand. $25 \%$ of enterprises need 5 10 people and 11 - 20 people each year, $21.43 \%$ of enterprises need 21 - 40 people each year, and $14.29 \%$ of enterprises need less than 5 people each year and more than 40 people each year.

Through investigation, it is found that enterprises have higher expectations for fishery professionals in higher vocational colleges. because fishery is a difficult industry, $53.57 \%$ of enterprises most expect to cultivate the spirit that fishery professionals in higher vocational colleges can endure hardship, and $25 \%$ of enterprises expect fishery professionals in higher vocational colleges to love to learn. $50 \%$ of enterprises are not satisfied with the current number of fishery 
professionals in higher vocational colleges, followed by the lack of professional stability (easy to change careers) of $32.14 \%$, lack of learning ability and lack of stamina. $75 \%$ of enterprises expect to cultivate professional and skilled talents of fishery specialty in higher vocational colleges. $67.86 \%$ expected to strengthen their professionalism and professional skills. $67.86 \%$ of enterprises require talents with strong self-management ability, while $17.86 \%$ of enterprises require talents with marketing awareness. $50 \%$ of enterprises require talents to communicate with each other and $35.71 \%$ require talents to have the ability to work independently. $50 \%$ of the enterprises think that the teaching reform of fishery specialty should pay attention to the teaching methods and methods, and $35.71 \%$ of the enterprises should pay attention to the latest technology.

In the next step of reform, efforts should be made to solve the problem of difficult professional enrollment and to cultivate the ability to bear hardships, love jobs, be dedicated and have strong skills. Cultivate students' sense of industry honor, let students love fishery specialty, properly strengthen theoretical knowledge, expand channels for upgrading, strengthen quality development training, and cultivate students' strong self-management ability, communication adaptability and ability to work independently.

\section{Acknowledgements}

This research was financially supported by Qing Lan Project of Jiangsu Province and Jiangsu Agri-animal Husbandry Vocational College, Social science project (Grant No. SKYB1715). It was also supported by China Vocational and technical education society, 2017-2018, teaching reform and textbook construction project (Grant No. 1710452), and project entrusted by the Vocational Education and Adult Education Department of the Ministry of Education (Grant No. 2018RCXQ01).

\section{References}

[1] China Government. The opinion of Central Committee of the Communist Party and the State Council of China on the implementation of the strategy of Rural Revitalization[J]. Chinese farmers' cooperative, 2018 (03): 7-16.

[2] China Government. Construction plan of modern vocational education system (2014-2020 years) [J]. Professional technology, 2014 (8).

[3] China Government. The Ministry of Agriculture issued the thirteenth five-year plan for national fisheries development [J]. Fisheries Science \& Technology Information, 2017 (2) :106-107

[4] Chen X, Sun Q. An Analysis of How to Offer the Vocational Guidance by Internet in China[C]// International Conference on Management, Education and Social Science. 2017.

[5]Chen X, Xiong L, Sun Q. Research and Practice on Innovation and Entrepreneurship Education System in Vocational Colleges[C]// International Conference on Management, Education and Social Science. 2017. 